\title{
Do Credit Rating Agencies Sacrifice Timeliness by Pursuing Rating Stability? Evidence from Equity Market Reactions to CreditWatch Events
}

\author{
Jenny Gu1 ${ }^{\text {, Jeffrey S. Jones }}{ }^{2}$, Pu Liu ${ }^{3}$ \\ ${ }^{1}$ College of Business, University of Dallas, Irving, USA \\ ${ }^{2}$ Department of Finance and General Business, Missouri State University, Springfield, USA \\ ${ }^{3}$ Sam M. Walton College of Business, University of Arkansas, Fayetteville, USA \\ Email: jgu@udallas.edu, JeffSJones@MissouriState.edu, pliu@walton.uark.edu
}

Received 3 April 2014; revised 3 May 2014; accepted 13 May 2014

Copyright (C) 2014 by authors and Scientific Research Publishing Inc.

This work is licensed under the Creative Commons Attribution International License (CC BY). http://creativecommons.org/licenses/by/4.0/

(c) (i) Open Access

\begin{abstract}
In this paper we examine how well CreditWatch is used by credit rating agencies to balance two conflicting goals: rating timeliness and rating stability. Examining equity market reactions around CreditWatch events in 2002-2005, we find evidence that while CreditWatch has improved rating timeliness, its intended purpose has not been completely achieved. Equity prices start to change days before companies are listed on CreditWatch and abnormal equity returns of firms prior to being listed on CreditWatch are effective predictors of the ultimate change in ratings. The findings in the study suggest that in the pursuit of rating stability, rating agencies may have sacrificed rating timeliness.
\end{abstract}

\section{Keywords}

CreditWatch, Credit Ratings, Rating Stability, Rating Timeliness

\section{Introduction}

One of the most surprising events during the 2007-2008 financial crisis was the filing of Chapter 11 bankruptcy by Lehman Brothers, an investment bank with a 158-year history, on Monday, September 15th, 2008. The news of Lehman's collapse shook financial markets world-wide, including a drop in the Dow Jones Industrial Average of more than 500 points. The collapse of Lehman took many investors by surprise because as recently as 
September 12th, the previous Friday, Lehman Brothers' bonds were rated "A", an investment grade.

Though unique in its impact on global markets, the precipitous fall of Lehman from investment grade status directly to bankruptcy is not unprecedented. Several other high-profile bankrupt companies, including Enron, also maintained investment-grade ratings until just days before the bankruptcy was announced. Are rating agencies too slow in adjusting ratings?

Indeed, one major criticism of credit rating agencies is the lack of timeliness in making rating changes. ${ }^{1}$ Studies in the finance literature have shown that credit rating changes are anticipated by the equity market (Norden and Weber [1]), the credit default swaps market (Hull, Predescu, and White [2]; Norden and Weber [1]), the currency market and the sovereign debt market (Reinhart [3], Sy [4]). Thus, credit rating agencies have faced such criticism long before the 2007-2008 financial crisis.

The challenges faced by rating agencies in conveying timely default information are multidimensional. In addition to the criticism for not being able to obtain timely information, for not using the best rating methodologies, and for not expending maximum effort (Goldstein, Kaminsky, and Reinhart [5]; Cheng and Neamtiu [6]), there are other deep-rooted reasons. First, while the financial positions of rated companies are constantly changing, the change in credit ratings can only be made periodically. As a result, a lag of credit ratings in reflecting the changes in financial positions may be inevitable. Secondly, default probability is a continuous variable, but credit ratings, which are indications of default likelihood, are discrete. A rating agency cannot make a rating change until the financial position of a company deteriorates to the next rating level. As a result, rating changes may lag the change in bond issuer's default probability. ${ }^{2}$

Another reason for the slow reaction may be related to an argument put forth by rating agencies that markets expect stable ratings. Ratings are often used by investors and regulators as guidance for portfolio governance. ${ }^{3}$ Frequent changes in ratings may force portfolio managers to trade securities more frequently, thereby increasing transaction costs. Frequent rating changes may also force portfolio managers to sell securities at lower prices (when they are downgraded) and to purchase at higher prices (when they are upgraded) more frequently and thus suffering more losses. Consequently, rating agencies tend to meet the market expectations by making rating changes only when a reversal in ratings in the near future is unlikely (Cantor [8]; Cantor and Mann [9]). Studies in the literature also show that the policy of issuing stable ratings allows rating agencies to focus on bond issuers' permanent, long-term and structural credit risk, rather than temporary, short-term and transitory credit risk (Altman and Rijken [10]). ${ }^{4}$

Rating agencies could have made rating changes as soon as they observe changes in bond issuers' credit risks, regardless of whether the changes in the credit risks are long-term or temporary. By doing so, however, rating agencies may have made rating changes too hastily and therefore have to make a reversal in rating changes to correct the previous overreactions. To avoid such a mistake, rating agencies would rather make gradual, stepwise, and sequential small changes in ratings, instead of making sudden, abrupt, and large rating changes and then making subsequent reverse rating changes to revise the previous changes. In balancing the two conflicting tasks, rating agencies choose the former over the latter. In other words, they would rather appear to be "slow" than to be "wrong".

Some studies (e.g. Loffler [11]), however, argue that such a policy of stable ratings may lead to a lag of rating changes behind the true changes in bond issuer's default risk. While investors may have some expectation of

\footnotetext{
${ }^{1}$ For instance, in response to the failure of Enron in December 2001, the Senate criticized credit rating agencies for not downgrading the company's debt rating soon enough. The Staff Report of the US Senate Committee on Governmental Affairs indicated that the credit agencies' monitoring and review of Enron's finances "fell below the careful efforts one would have expected from organizations whose ratings hold so much importance”.

${ }^{2}$ Both Moody’s Investors Service and Standard \& Poor's have adopted refined rating categories by adding modifiers (e.g. “+” and “-”, or " 1 ", " 2 ", and " 3 ") to the generic rating categories to indicate whether a bond is on the upper, middle, or lower end of the rating category. The refinement of the rating categories can be viewed as a step moving from a discrete rating system toward a continuous spectrum. So refined ratings not only reflect the default probability more precisely, they also may trigger a rating change more quickly as rating agencies do not have to wait until the financial positions of bond issuers to deteriorate (or improve) to the next broader generic rating category to make rating changes.

${ }^{3}$ For instance, financial institutions such as banks, insurance companies, money market funds, and pension funds are often required to hold "investment grade" bonds only in order to show their "prudence" in fund management by laws and regulations. As a result, when a bond is downgraded to "speculative grade”, they must sell the bond at a loss. In fact, Zweig [7] indicated that since 1930s, more than 150 such laws and regulations have been implemented.

${ }^{4}$ Standard \& Poor's (2003) indicates that the value of its rating products is greatest "when its ratings focus on the long-term and do not fluctuate with short-term performance”. Similarly, Moody’s Investors Service makes rating changes "only when it believes an issuer has experienced what is likely to be an enduring change in fundamental credit worthiness” (Cantor and Mann [12]).
} 
rating stability, they also expect rating agencies to make changes in a timely fashion. If rating agencies sacrifice timeliness for the sake of stability, markets may work faster than the rating agency and price in much of information about the changing default risk of the firm before a rating change occurs. They argue that investors would benefit from timely rating changes, especially during financial crises when investors are urgently seeking new information about the default risk of a firm.

Credit rating agencies have not been insensitive to the criticism. One specific action by Standard and Poor's (S\&P's) was the creation in a service known as CreditWatch, which was first offered in November 1981. CreditWatch provides information to investors about potential changes in default risk prior to an actual change in rating. One major purpose of CreditWatch is to ease the tension between the market expectation of rating stability and the market demand for rating timeliness (Altman and Rijken [13]).

When a company is listed on CreditWatch, it is typically listed with either a positive or a negative potential. ${ }^{5}$ In a listing with positive potential, the rating of the company will usually be eventually upgraded or affirmed (i.e. unchanged), and the rating is rarely downgraded. Similarly, in a listing with negative potential, the rating of the company will usually be eventually downgraded or affirmed, and the rating is rarely upgraded. Once the rating is changed or affirmed, the listed company is delisted (removed) from the CreditWatch list. Unlike credit rating changes in which rating agencies convey the default risk to the market in one action (i.e. the rating change), the publication of CreditWatch conveys the default information to the market through two sequential actions-first through listing, and then through delisting. The listing conveys information about the direction of the rating change, and the delisting reveals the magnitude of the actual rating change. Although listing on CreditWatch can lead to a bond rating change, only a small fraction of all actual rating changes are preceded by a listing on CreditWatch.

In this study, we examine the response of equity prices of firms listed and delisted from CreditWatch to determine if CreditWatch improves the timeliness of rating changes. Despite its intended purpose of informing investors of a potential rating change in a timely fashion, we find that CreditWatch does not completely achieve this goal. We report three major findings in support of this conclusion. First, we find equity markets experience substantial positive (negative) reaction to the listing of companies with positive (negative) potential on CreditWatch prior to the actual date of listing. Furthermore, the magnitude of pre-listing abnormal returns is closely correlated to the magnitude of rating changes the follow the listing date. These results suggest that rating agencies are still slow in conveying information about the change in default risk to the market. Second, equity markets exhibit significant abnormal returns on the CreditWatch listing day, but exhibit little reaction to the removal of a company from CreditWatch. The results indicate that the impact of rating agency's announcement has moved forward from rating changes to CreditWatch listings that precede the rating changes. The results suggest that CreditWatch listing improved the timeliness of rating functions. Collectively, the findings in the study suggest that while CreditWatch mitigates the problem of the lack of timeliness by bringing forward its impact from the subsequent rating change to the CreditWatch listing, it does not completely resolve the timeliness issue caused by rating stability policy. Third, to further confirm the conclusion, we also use the abnormal returns surrounding the CreditWatch listing date to predict the magnitude of subsequent rating changes and find that the abnormal returns surrounding the CreditWatch listing date indeed serve a good predictor for the rating changes subsequent to the CreditWatch listing. Collectively, our findings suggest that rating agencies may sacrifice timeliness for the sake of stability and that even CreditWatch, which is designed to mitigate the disadvantage caused by stable rating policies, is not a completely effective instrument.

The remainder of the paper is organized as follows. Section 2 discusses the data and the methodology. Section 3 presents the empirical analyses and results, and Section 4 concludes.

\section{Data and Methodology}

Our sample construction begins with firms placed on CreditWatch between January 2002 and December 2005. We hand-collect the following data for firms at the time of listing: 1) company name, 2) listing date, 3) existing S\&P senior debt rating, and 4) listing potential. From this group, we exclude all firms with insufficient data from the Center in Research and Security Prices (CRSP) to compute abnormal returns surrounding the listing date.

\footnotetext{
${ }^{5}$ Infrequently, Standard \& Poor's will place a company on the CreditWatch list under a third category known as "developing”. When a company is listed as "developing", it means the credit rating of the company is likely to be changed, but the direction of the change is unknown. The number of companies listed as "developing" is far less than the number of companies listed with positive or negative potentials. We do not include bonds listed as "developing” in our study.
} 
We also exclude firms for which definitive information about the action taken by S\&P regarding the firms' rating upon delisting is unavailable. The final sample consists of 604 observations, with 101 listed with "positive" potential, 503 listed with "negative" potential. ${ }^{6}$ The sample composition is consistent with similar studies in the literature (e.g. Dichev and Piotroski [14]; Hand, Holthausen, and Leftwich [15]; Holthausen, and Leftwich [16]) in that downgrades are considerably more common than upgrades.

Following Morgan [17], we transform letter ratings into a numerical scale with higher quality ratings transformed into lower numbers. To save space, we don't include raw data here. By observing the data of listings with positive potential, approximately $80 \%$ of firms are upgraded when delisted from CreditWatch. For firms listed with negative potential, approximately $60 \%$ are downgraded when delisted.

Financial data is obtained from Compustat for the year preceding the date of listing. The sample sizes are reduced slightly because of missing data in Compustat. Statistically significant differences exist regarding the size of the companies (measured by total assets) and the cash ratio. Specifically, firms listed with negative potential are larger in size and have lower cash ratios compared to firms listed with positive potential. Firms listed with positive potential tend to remain on the CreditWatch list longer than those listed with negative potential, but the difference is not statistically significant.

To capture the reaction of the equity market, we employ an event study methodology by computing daily abnormal returns (AR) and cumulative abnormal returns (CAR) of the companies in event windows surrounding the listing and delisting dates. For robustness, we consider three estimation procedures-the market model, market adjusted return model, and the Fama-French (1992) model - to calculate the abnormal returns. The market index is the CRSP value-weighted index and the daily Fama-French factors are also obtained from CRSP. The estimation period is the 200 trading days ending 61 trading days prior to the event date.

\section{Empirical Results}

Our goal in this paper is evaluating the ability of CreditWatch to convey information to markets in a timely fashion. Accordingly, we examine the equity market's reaction to both the listing on and delisting from CreditWatch. We also examine to what extent the rating action that occurs upon delisting (i.e. an affirmed rating or a change in rating) is reflected in the abnormal returns.

\subsection{Equity Market Reaction to CreditWatch Listing}

To assess whether CreditWatch listings reflect the changes of the listed companies' financial positions in a timely fashion, we calculate the daily AR on days surrounding the date of listing and the CAR for several event windows. For robustness, we use three different return generating models, as described in the previous section. Separate results of the mean values for listings with positive and negative potential are presented in Table 1.

Analysis of the daily AR shows a significant positive (negative) reaction by the market on the day of a listing (Day 0) with positive (negative) potential. Taken alone, this finding suggests that a listing on CreditWatch provides the market with new information. However, the magnitude of the reaction on the day of listing is often substantially smaller than the CAR present in the days prior to the listing date, suggesting the listing on CreditWatch is somewhat delayed. This trend is particularly pronounced for those firms listed with negative potential. For example, the market adjusted model abnormal return on Day 0 is $-2.84 \%$, but CAR $(-30,-1)$ is nearly three times as large at $-8.20 \%$.

Although the abnormal returns are both statistically and economically significant on the listing day, we cannot conclude whether the return on the listing day was due to the announcement of the CreditWatch list, or it is part of the continuing adjustment process that may have started as early as 60 days before the listing. Even if the significant abnormal return on the listing day is entirely related to the announcement of the listing, the results still indicate the placement of firms on CreditWatch may not be timely enough. ${ }^{7}$ Regardless of the specification for computing abnormal returns (the market model, market adjusted return model, or the Fama-French model), the results in Table 2 suggest that equity markets have reflected a substantial portion of the change in listed firms' financial positions before the listing day. For robustness, we also examine the median values of the daily AR

\footnotetext{
${ }^{6}$ There is one (five) extremely rare cases in which firms were listed with positive (negative) potentials but were downgraded (upgraded). We report these observations in our descriptive statistics, but exclude them from further analysis.

${ }^{7}$ This position is consistent with the study of Liu and Thakor [18] who report that information conveyed by rating agencies has an independent impact on secure ties prices over and above publicly available financial and economic information.
} 
Table 1. Equity market reaction to CreditWatch listing.

\begin{tabular}{|c|c|c|c|c|c|c|c|c|c|c|c|c|}
\hline \multirow{2}{*}{$\begin{array}{l}\text { AR } \\
\text { Day }\end{array}$} & \multicolumn{6}{|c|}{ Firms with Positive Potentials } & \multicolumn{6}{|c|}{ Firms with Negative Potentials } \\
\hline & MKT Model & & MADJ Model & & FF Model & & MKT Model & & MADJ Model & & FF Model & \\
\hline-7 & $0.08 \%$ & & $0.26 \%$ & & $0.11 \%$ & & $-0.28 \%$ & $* *$ & $-0.31 \%$ & $* *$ & $-0.26 \%$ & \\
\hline-6 & $-0.07 \%$ & & $-0.01 \%$ & & $-0.11 \%$ & & $-0.32 \%$ & $* * *$ & $-0.38 \%$ & $* * *$ & $-0.32 \%$ & $* * *$ \\
\hline-5 & $0.15 \%$ & & $0.39 \%$ & & $0.09 \%$ & & $-0.76 \%$ & $* * *$ & $-0.77 \%$ & $* * *$ & $-0.69 \%$ & \\
\hline-4 & $0.34 \%$ & $*$ & $0.43 \%$ & $* *$ & $0.36 \%$ & & $-0.24 \%$ & $*$ & $-0.32 \%$ & $* *$ & $-0.24 \%$ & \\
\hline-3 & $0.78 \%$ & $* * *$ & $0.78 \%$ & $* * *$ & $0.70 \%$ & $* *$ & $-0.21 \%$ & * & $-0.24 \%$ & $*$ & $-0.21 \%$ & $* * *$ \\
\hline-2 & $0.20 \%$ & $* *$ & $0.34 \%$ & $* * *$ & $0.11 \%$ & $* *$ & $-0.75 \%$ & $* * *$ & $-0.82 \%$ & $* * *$ & $-0.68 \%$ & $* *$ \\
\hline-1 & $-0.10 \%$ & & $0.13 \%$ & & $-0.12 \%$ & & $-1.41 \%$ & $* * *$ & $-1.46 \%$ & $* * *$ & $-1.40 \%$ & $* * *$ \\
\hline 0 & $2.71 \%$ & $* * *$ & $2.79 \%$ & $* * *$ & $2.67 \%$ & $* *$ & $-2.83 \%$ & $* * *$ & $-2.84 \%$ & $* * *$ & $-2.86 \%$ & $* * *$ \\
\hline 1 & $0.18 \%$ & & $0.27 \%$ & & $0.26 \%$ & * & $-1.14 \%$ & $* * *$ & $-1.18 \%$ & $* * *$ & $-1.11 \%$ & $* * *$ \\
\hline 2 & $0.01 \%$ & & $0.09 \%$ & & $0.03 \%$ & & $-0.24 \%$ & $* *$ & $-0.26 \%$ & $* *$ & $-0.27 \%$ & $* *$ \\
\hline 3 & $-0.05 \%$ & & $0.03 \%$ & & $0.01 \%$ & & $0.25 \%$ & * & $0.20 \%$ & & $0.28 \%$ & \\
\hline CAR & \multicolumn{6}{|c|}{ Firms with Positive Potentials } & \multicolumn{6}{|c|}{ Firms with Negative Potentials } \\
\hline Days & MKT Model & & MADJ Model & & FF Model & & MKT Model & & MADJ Model & & FF Model & \\
\hline$(-60,-1)$ & $3.78 \%$ & $* * *$ & $10.01 \%$ & $* * *$ & $2.89 \%$ & $* *$ & $-7.11 \%$ & $* * *$ & $-10.82 \%$ & $* * *$ & $-7.08 \%$ & $* * *$ \\
\hline$(-30,-1)$ & $1.64 \%$ & $* *$ & $4.85 \%$ & $* * *$ & $1.37 \%$ & $*$ & $-6.23 \%$ & $* * *$ & $-8.20 \%$ & $* * *$ & $-5.95 \%$ & $* * *$ \\
\hline$(-7,-1)$ & $1.39 \%$ & $* * *$ & $2.32 \%$ & $* * *$ & $1.16 \%$ & & $-3.97 \%$ & $* * *$ & $-4.32 \%$ & $* * *$ & $-3.80 \%$ & $* * *$ \\
\hline$(0,0)$ & $2.71 \%$ & $* * *$ & $2.79 \%$ & $* * *$ & $2.67 \%$ & $* *$ & $-2.83 \%$ & $* * *$ & $-2.84 \%$ & $* * *$ & $-2.86 \%$ & $* * *$ \\
\hline$(+1,+3)$ & $0.13 \%$ & & $0.40 \%$ & & $0.29 \%$ & & $-1.13 \%$ & $* * *$ & $-1.24 \%$ & $* * *$ & $-1.10 \%$ & $* *$ \\
\hline $\mathrm{N}$ & 101 & & 101 & & 101 & & 503 & & 503 & & 503 & \\
\hline
\end{tabular}

This table presents the mean values of the daily abnormal returns (AR) and cumulative abnormal returns (CAR) over various event windows surrounding the listing day on CreditWatch. Results are presented separately based on the expected rating change potential (positive or negative) at the time of listing. The AR and CAR are calculated using three models as described in Section 1: the market model (MKT), the market adjusted return model (MADJ), and the Fama-French 3 -factor model (FF). *, **, *** denotes statistically different from zero based on a Patell $\mathrm{z}$-test at the $10 \%, 5 \%$ and $1 \%$ levels, respectively.

and CAR, and the results (unreported) confirm the findings of the analysis using the value of the means.

We next examine the equity market reaction surrounding the listing date categorized by the delisting action. We classify the listed companies into four categories based on the magnitude of the actual change in rating that occurs on the delisting day. The four categories are: no rating change (i.e. rating being affirmed), a small rating change (changed by one notch), a medium rating change (changed by two notches), and a large rating change (changed by three notches or more). The subcategories are further separated for companies listed with positive and negative potential, creating a total of eight possible categories. The mean daily AR and CAR over various event windows surrounding the listing date for each category are presented in Table 2 . To conserve space, we report only the results from the market model estimation throughout the remainder of the paper, but both the market adjusted return model and the Fama-French models produces results qualitatively similar to those from the market model.

From Table 2 we note that the on listing day the abnormal returns are still statistically significant for each category even after we classify the returns by the magnitude of rating changes. The results suggest that CreditWatch listings have an impact on the equity market. However, the results in Table 2 also provide considerable evidence suggesting a positive correlation between the magnitude of the CARs prior to the listing day and the magnitude of the rating changes announced on the delisting day. For positively listed companies, the magnitude of the CARs prior to the listing day does not monotonically increase with the magnitude of rating changes, but we find the average magnitude of the CARs for companies within the two smallest rating change categories (i.e. companies whose ratings were affirmed or were changed by one notch) are smaller than the CARs for companies with two larger rating change categories (i.e. companies whose ratings were changed by two notches or three notches or more).

For companies listed with negative potentials (which is a much larger sample compared to the listings with 
Table 2. Equity market reaction to CreditWatch listing categorized by delisting action.

\begin{tabular}{|c|c|c|c|c|c|c|c|c|c|c|c|c|c|c|c|c|}
\hline AR & & & & Pos & itive & & & & & & & Nega & ative & & & \\
\hline Day & Affirmed & & $\begin{array}{l}\text { Up } 1 \\
\text { Notches }\end{array}$ & & $\begin{array}{c}\text { Up } 2 \\
\text { Notches }\end{array}$ & & $\begin{array}{c}\text { Up 3+ } \\
\text { Notches }\end{array}$ & & Affirmed & & $\begin{array}{l}\text { Down } 1 \\
\text { Notches }\end{array}$ & & $\begin{array}{l}\text { Down } 2 \\
\text { Notches }\end{array}$ & & $\begin{array}{c}\text { Down 3+ } \\
\text { Notches }\end{array}$ & \\
\hline-7 & $0.66 \%$ & & $0.14 \%$ & & $-0.17 \%$ & & $-0.76 \%$ & & $-0.07 \%$ & & $-0.25 \%$ & $*$ & $-0.88 \%$ & $* *$ & $-0.21 \%$ & \\
\hline-6 & $-0.32 \%$ & & $-0.12 \%$ & & $-0.55 \%$ & & $0.77 \%$ & & $-0.29 \%$ & $* *$ & $-0.12 \%$ & & $-1.53 \%$ & $* * *$ & $0.39 \%$ & \\
\hline-5 & $-0.06 \%$ & & $0.09 \%$ & & $0.90 \%$ & * & $0.16 \%$ & & $-0.13 \%$ & & $-0.86 \%$ & $* * *$ & $-1.61 \%$ & $* * *$ & $-1.18 \%$ & $*$ \\
\hline-4 & $0.02 \%$ & & $0.01 \%$ & & $2.42 \%$ & $* * *$ & $0.35 \%$ & & $-0.02 \%$ & & $-0.46 \%$ & $* * *$ & $-0.03 \%$ & & $-0.23 \%$ & \\
\hline-3 & $0.55 \%$ & & $0.34 \%$ & $*$ & $3.91 \%$ & $* * *$ & $0.31 \%$ & & $0.14 \%$ & & $-0.29 \%$ & $* *$ & $-0.34 \%$ & & $-1.13 \%$ & \\
\hline-2 & $-0.24 \%$ & & $0.00 \%$ & & $-0.42 \%$ & & $1.75 \%$ & $* * *$ & $-0.54 \%$ & $* * *$ & $-0.17 \%$ & $* *$ & $-1.13 \%$ & $* * *$ & $-4.17 \%$ & $* * *$ \\
\hline-1 & $0.19 \%$ & & $-0.68 \%$ & $*$ & $1.41 \%$ & $* * *$ & $0.49 \%$ & & $-0.87 \%$ & $* * *$ & $-1.74 \%$ & $* * *$ & $-1.05 \%$ & $* * *$ & $-3.20 \%$ & $* * *$ \\
\hline 0 & $4.84 \%$ & $* * *$ & $0.07 \%$ & $* *$ & $4.24 \%$ & $* * *$ & $8.94 \%$ & $* * *$ & $-0.65 \%$ & $* *$ & $-3.74 \%$ & $* * *$ & $-2.89 \%$ & $* * *$ & $-8.63 \%$ & $* * *$ \\
\hline 1 & $0.48 \%$ & & $0.17 \%$ & & $-0.11 \%$ & & $0.00 \%$ & & $-0.78 \%$ & $* * *$ & $-0.80 \%$ & $* * *$ & $-1.43 \%$ & $* * *$ & $-3.95 \%$ & $* * *$ \\
\hline 2 & $-0.14 \%$ & & $-0.18 \%$ & & $1.34 \%$ & $* *$ & $0.04 \%$ & & $-0.29 \%$ & & $-0.45 \%$ & $* * *$ & $-0.30 \%$ & & $0.95 \%$ & \\
\hline 3 & $-0.77 \%$ & & $0.22 \%$ & & $0.23 \%$ & & $-0.30 \%$ & & $0.07 \%$ & & $0.03 \%$ & & $0.53 \%$ & * & $1.51 \%$ & $* *$ \\
\hline CAR & & & & Pos & itive & & & & & & & Nega & ative & & & \\
\hline Day & Affirmed & & $\begin{array}{c}\text { Up } 1 \\
\text { Notches }\end{array}$ & & $\begin{array}{c}\text { Up } 2 \\
\text { Notches }\end{array}$ & & $\begin{array}{l}\text { Up 3+ } \\
\text { Notches }\end{array}$ & & Affirmed & & $\begin{array}{l}\text { Down } 1 \\
\text { Notches }\end{array}$ & & $\begin{array}{l}\text { Down } 2 \\
\text { Notches }\end{array}$ & & $\begin{array}{c}\text { Down 3+ } \\
\text { Notches }\end{array}$ & \\
\hline$(-60,-1)$ & $7.53 \%$ & * & $-0.48 \%$ & & $11.02 \%$ & $* * *$ & $6.36 \%$ & $*$ & $-1.83 \%$ & $* * *$ & $-7.68 \%$ & $* * *$ & $-12.66 \%$ & $* * *$ & $-23.69 \%$ & $* * *$ \\
\hline$(-30,-1)$ & $5.53 \%$ & & $-1.94 \%$ & & $9.84 \%$ & $* * *$ & $3.01 \%$ & & $-2.08 \%$ & $* * *$ & $-7.09 \%$ & $* * *$ & $-10.70 \%$ & $* * *$ & $-18.20 \%$ & $* * *$ \\
\hline$(-7,-1)$ & $0.80 \%$ & & $-0.23 \%$ & & $7.51 \%$ & $* * *$ & $3.07 \%$ & $* *$ & $-1.78 \%$ & $* * *$ & $-3.88 \%$ & $* * *$ & $-6.58 \%$ & $* * *$ & $-9.72 \%$ & $* * *$ \\
\hline$(0,0)$ & $4.84 \%$ & $* * *$ & $0.07 \%$ & $* *$ & $4.24 \%$ & $* * *$ & $8.94 \%$ & $* * *$ & $-0.65 \%$ & $* *$ & $-3.74 \%$ & $* * *$ & $-2.89 \%$ & $* * *$ & $-8.63 \%$ & $* * *$ \\
\hline$(+1,+3)$ & $-0.44 \%$ & & $0.21 \%$ & & $1.46 \%$ & & $-0.26 \%$ & & $-0.99 \%$ & $* * *$ & $-1.22 \%$ & $* * *$ & $-1.19 \%$ & $* *$ & $-1.50 \%$ & $* * *$ \\
\hline $\mathrm{N}$ & 20 & & 55 & & 11 & & 14 & & 193 & & 199 & & 68 & & 38 & \\
\hline
\end{tabular}

This table presents the mean values of daily abnormal returns (AR) and cumulative abnormal returns (CAR) over various event windows surrounding the listing date on CreditWatch categorized by the change in rating that occurs when the firm is delisted. The AR and CAR are computed using the market model as described in Section 1. The sample size is reduced because firms delisted with rating changes in an opposite direction of the initial listing are excluded from analysis. Separate results are presented for firms listed with positive and negative potential. Within the categories of positive (negative) potential, results are further classified by the magnitude of delisting action: affirmed with no change in rating, up (down) by one notch, up (down) by two notches, or up (down) by three or more notches. Abnormal returns generated by both the market adjusted return model and Fama-French 3 -factor model produce qualitatively similar results and are not reported. *, **, *** denotes statistically different from zero based on a Patell z-test at the $10 \%, 5 \%$ and $1 \%$ levels, respectively.

positive potential), the evidence is much stronger. The magnitude of the CAR prior to the listing, regardless of the event window, exhibits a consistent monotonic trend. This is strong evidence that equity markets have anticipated prior to the listing date not only the CreditWatch listing potential (positive or negative), but also the change in rating at delisting. This point is well-illustrated in Figure 1, which plots CAR $(-7,+3)$ for the eight categories. Despite some notable reaction on the day of announcement, the adjustment process in equity prices begins well before then, particularly for listings that ultimately result in rating changes of at least two notches. The results suggest that while CreditWatch has an impact on equity prices upon listing announcement, it is still not timely enough in conveying the information about the change of financial positions of listed firms to the market.

\subsection{Equity Market Reaction to CreditWatch Delisting}

Having provided evidence that the magnitude of the rating change at delisting is reflected in equity prices prior to the listing announcement, we next examine the information content of the delisting event by computing the AR and CAR surrounding the date of delisting.

Table 3 presents the daily AR and CAR over various event windows surrounding the delisting date by the type of action that occurs when the company is delisted from CreditWatch. We take care to ensure that none of the pre-delisting windows overlap with post-listing windows. The results in Table 3 are noticeably different from those presented in Table 2 for the listing date, as there is very little market reaction on the day of the de- 


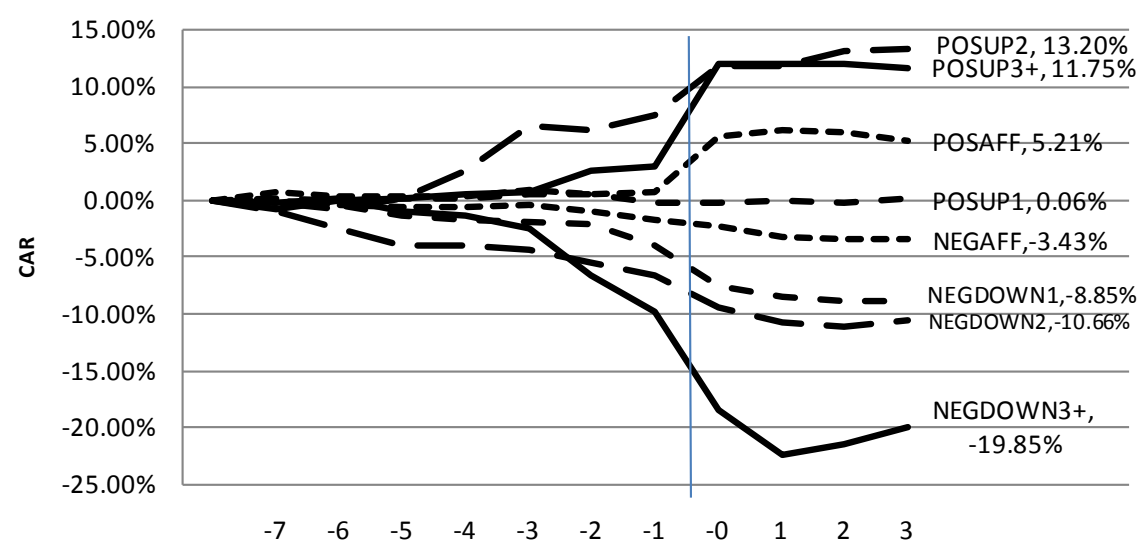

Figure 1. Cumulative abnormal returns surrounding the listing date categorized by delisting action. This figure presents the mean cumulative abnormal returns (CARs) surrounding the listing date (defined at $\mathrm{t}=0$ ) from seven days before to three days after the listing day $(-7,+3)$, categorized by the delisting action. POS_AFF is listed with positive potential followed by rating affirmation (i.e. unchanged) upon delisting. POS_UP1, POS_UP2, and POS_UP3+ are listed with positive potential followed by upgrade of 1,2 , and 3 or more notches, respectively, upon delisting. NEG_AFF is listed with negative potential followed by rating affirmation upon delisting. NEG_DOWN1, NEG_DOWN2, and NEG_DOWN3+ are listed with negative potential followed by downgrade of 1 , 2, and 3 or more notches, respectively, upon delisting.

Table 3. Equity market reaction to CreditWatch delisting.

\begin{tabular}{|c|c|c|c|c|c|c|c|c|c|c|c|c|c|c|c|}
\hline AR & & Firr & ms Listed & ith I & ositive Pot & ential & & & & Firms Listec & witl & Negative & Potent & & \\
\hline Day & Affirmed & & $\begin{array}{l}\text { Up } 1 \\
\text { Notches }\end{array}$ & & $\begin{array}{c}\text { Up } 2 \\
\text { Notches }\end{array}$ & & $\begin{array}{l}\text { Up 3+ } \\
\text { Notches }\end{array}$ & & Affirmed & $\begin{array}{l}\text { Down } 1 \\
\text { Notches }\end{array}$ & & $\begin{array}{l}\text { Down } 2 \\
\text { Notches }\end{array}$ & & $\begin{array}{c}\text { Down 3+ } \\
\text { Notches }\end{array}$ & \\
\hline-7 & $-3.31 \%$ & $* * *$ & $-0.58 \%$ & & $0.23 \%$ & & $-1.53 \%$ & & $0.01 \%$ & $-0.37 \%$ & $*$ & $-1.49 \%$ & $* * *$ & $4.95 \%$ & $* * *$ \\
\hline-6 & $1.04 \%$ & $* *$ & $0.18 \%$ & $*$ & $-0.49 \%$ & & $-1.66 \%$ & * & $0.22 \%$ & $-0.42 \%$ & & $-2.07 \%$ & $* * *$ & $1.05 \%$ & $* * *$ \\
\hline-5 & $-0.93 \%$ & $* * *$ & $-1.01 \%$ & $* *$ & $-0.53 \%$ & & $-0.98 \%$ & & $-0.15 \%$ & $-0.13 \%$ & & $0.43 \%$ & & $-1.22 \%$ & $* *$ \\
\hline-4 & $-0.34 \%$ & & $0.63 \%$ & & $0.24 \%$ & & $-0.55 \%$ & & $0.19 \%$ & $0.59 \%$ & $*$ & $0.33 \%$ & & $0.84 \%$ & \\
\hline-3 & $0.10 \%$ & & $-0.42 \%$ & & $-0.38 \%$ & & $-0.43 \%$ & & $0.11 \%$ & $0.57 \%$ & $*$ & $-0.85 \%$ & $* *$ & $0.57 \%$ & $* *$ \\
\hline-2 & $-0.20 \%$ & & $0.29 \%$ & & $0.18 \%$ & & $-1.84 \%$ & & $0.26 \%$ & $-0.01 \%$ & & $0.01 \%$ & & $-2.98 \%$ & $* * *$ \\
\hline-1 & $-0.03 \%$ & & $-0.16 \%$ & & $-1.48 \%$ & * & $1.18 \%$ & & $0.04 \%$ & $0.35 \%$ & $*$ & $0.15 \%$ & & $-0.87 \%$ & \\
\hline 0 & $-0.55 \%$ & & $-0.62 \%$ & $* *$ & $0.65 \%$ & & $-0.36 \%$ & & $0.28 \%$ & $-0.07 \%$ & & $1.04 \%$ & $* * *$ & $-1.49 \%$ & $* * *$ \\
\hline 1 & $0.56 \%$ & & $0.50 \%$ & $*$ & $0.64 \%$ & & $0.39 \%$ & & $0.10 \%$ & $0.16 \%$ & & $-0.69 \%$ & $* *$ & $0.94 \%$ & $* *$ \\
\hline 2 & $-0.26 \%$ & & $1.37 \%$ & * & $-1.72 \%$ & $* *$ & $-0.46 \%$ & & $0.13 \%$ & $0.22 \%$ & & $-0.24 \%$ & & $0.12 \%$ & \\
\hline 3 & $0.07 \%$ & & $0.17 \%$ & & $-0.19 \%$ & & $-0.42 \%$ & & $0.22 \%$ & $0.47 \%$ & $* *$ & $-1.26 \%$ & $* *$ & $2.29 \%$ & $* * *$ \\
\hline CAR & & Firr & ms Listed & ith I & ositive Po & ential & & & & Firms Listed & witl & Negative & Potent & & \\
\hline Day & Affirmed & & $\begin{array}{l}\text { Up } 1 \\
\text { Notches }\end{array}$ & & $\begin{array}{l}\text { Up } 2 \\
\text { Notches }\end{array}$ & & $\begin{array}{l}\text { Up 3+ } \\
\text { Notches }\end{array}$ & & Affirmed & $\begin{array}{l}\text { Down } 1 \\
\text { Notches }\end{array}$ & & $\begin{array}{l}\text { Down } 2 \\
\text { Notches }\end{array}$ & & $\begin{array}{c}\text { Down 3+ } \\
\text { Notches }\end{array}$ & \\
\hline$(-7,-1)$ & $-3.66 \%$ & $* * *$ & $-1.07 \%$ & & $-2.23 \%$ & & $-5.82 \%$ & * & $0.68 \%$ & $0.59 \%$ & & $-3.50 \%$ & $* *$ & $2.35 \%$ & \\
\hline$(0,0)$ & $-0.55 \%$ & & $-0.62 \%$ & $* *$ & $0.65 \%$ & & $-0.36 \%$ & & $0.28 \%$ & $-0.07 \%$ & & $1.04 \%$ & $* *$ & $-1.49 \%$ & $* * *$ \\
\hline$(+1,+3)$ & $0.37 \%$ & & $2.05 \%$ & $*$ & $-1.27 \%$ & & $-0.49 \%$ & & $0.44 \%$ & $0.85 \%$ & $*$ & $-2.16 \%$ & $* *$ & $3.35 \%$ & $* * *$ \\
\hline $\mathrm{N}$ & 19 & & 49 & & 8 & & 6 & & 191 & 196 & & 63 & & 32 & \\
\hline
\end{tabular}

This table presents the mean values of daily abnormal returns (AR) and cumulative abnormal returns (CAR) over various event windows surrounding the date of delisting from CreditWatch. The AR and CAR are computed using the market model as described in Section 1. The sample size is reduced because firms delisted with rating changes in an opposite direction of the initial listing are excluded from analysis. Separate results are presented for firms listed with positive and negative potential. Within the categories of positive (negative) potential, results are further classified by the magnitude of delisting action: affirmed with no change in rating, up (down) by one notch, up (down) by two notches, or up (down) by three or more notches. Abnormal returns generated by both the market adjusted return model and Fama-French 3-factor model produce qualitatively similar results and are not reported. ${ }^{* *}, * * *$ denotes statistically different from zero based on a standard t-test at the $10 \%, 5 \%$ and $1 \%$ levels, respectively. 
listing announcement (Day 0). This is true regardless of whether the firm was listed with positive or negative potential, and also irrespective of the magnitude of the rating change upon delisting. The results suggest that the announcement of delisting (in which the actual rating changes are made) contains limited information. Collectively, the results in Table 2 and Table 3 suggest that while CreditWatch service has moved forward some of its impact from rating change day to the CreditWatch day and thus improved the timeliness of rating functions, the timeliness issue has not been completely resolved as most of the abnormal returns start many days before the listing day.

\subsection{Predicting the Change in Rating}

We have shown that CreditWatch service improved the information release timing and moved forward the impact on equity prices from rating change day to the CreditWatch listing day. However, we have also shown the improvement in rating timeliness is not complete and the timeliness issue is not fully resolved because equity markets experience significant reactions in the days prior to a firm's listing day.

To further confirm that rating agencies are still issuing default risk information timely enough, we now examine whether the pre-listing equity market reaction is an effective predictor of the eventual change in rating upon delisting. If it is, then the CreditWatch is too slow in reflecting the changes in the firms' financial positions.

While the results in Table 2 and Figure 1 suggest that pre-listing CARs may serve as good predictors of rating changes, we now provide additional statistical support. To ascertain the degree of statistical significance, we regress the magnitude of the rating change at delisting on the CARs from the listing period using OLS estimation. Recall that higher rated bonds receive lower numerical scores, so an upgrade (downgrade) results in a negative (positive) value for the dependent variable. The results for several specifications of this model are presented in Table 4.

Model 1 contains only the CARs from the listing period as independent variables. ${ }^{8}$ The CARs for both the pre-listing (LIST_CAR $(-7,-1)$ ) and listing date (LIST_CAR $(0,0))$ are negative and statistically significant, and an F-test for the equality of coefficients shows that the magnitude of the listing date CAR is significantly greater. This suggests that the announcement day contains significantly more information than the pre-listing period. However, the inclusion of additional control variables eliminates this statistical difference.

Model 2 adds control variables for the time between the listing and delisting dates (SPAN) and the initial numerical rating at the time of listing (LIST_RATING). We also include dummy variables to control for proximity to the threshold between investment-grade and speculative-grade (junk) status. A bond rating of BB+ and below is considered junk status. Prior studies (e.g. Brister, Kennedy, and Liu [19]; Jorion and Zhang [20]) have demonstrated movement into or out of junk status has a more pronounced impact on markets since many institutional investors are prohibited from holding junk bonds. NEAR_JUNK takes a value of one for negatively listed firms with an initial rating of $\mathrm{BBB}+$, BBB, or BBB-. NEAR_JUNK bonds are most likely to be downgraded into the junk bond categories upon delisting. Similarly, NEAR_INVESTMENT takes a value of one for positively listed firms with an initial rating of $\mathrm{BB}+$, BB, or BB-. NEAR_INVESTMENT bonds are most likely to be upgraded into investment-grade categories upon delisting. The addition of these two dummy variables reduce the magnitude of LIST_CAR $(0,0)$, but both LIST_CAR $(-7,-1)$ and LIST_CAR $(0,0)$ retain statistical significance. Model 3 includes an interaction of the dummy variables NEAR_JUNK and NEAR_INVESTMENT with LIST_ CAR $(-7,-1)$. The interaction of LIST_CAR $(-7,-1)$ with NEAR_JUNK is positive and significant.

Model 4 adds basic financial characteristics of the listed firms as control variables. We include the natural log of assets, LN (ASSETS), as measure of size, ROA as a measure of profitability, DEBT_RATIO as a measure of leverage, and CASH_RATIO as a measure of liquidity, but none of the variables have a statistically significant impact on the magnitude of the rating change.

As a robustness check, Models 5 and 6 repeat the variable structure of Model 4, but separate the observations into categories of positive and negative potentials, respectively. Separating the sample into these two categories results in a truncation of the dependent variable (i.e. the change in rating), so we estimate Models 5 and 6 using a Tobit procedure. The results for both Models 5 and 6 are consistent with the findings in Models 1 through 4 . The pre-listing and listing day CARs are statistically related to the change in rating upon delisting.

\footnotetext{
${ }^{8}$ We also consider the potential correlation between CARs surrounding the listing date. To address this issue, we run the regression of Table 4 model (4) OLS by including only one CAR each time and previous results still hold. The concern of possible correlation between CARs is relieved.
} 
Table 4. Predicting the magnitude of rating change at delisting.

\begin{tabular}{|c|c|c|c|c|c|c|c|c|c|c|c|c|}
\hline \multirow{3}{*}{$\begin{array}{c}\text { Dependent Variable: Rating } \\
\text { Change }\end{array}$} & \multicolumn{8}{|c|}{ Both Positive and Negative } & \multirow{2}{*}{\multicolumn{2}{|c|}{$\begin{array}{l}\text { Positive } \\
\text { (5) Tobit }\end{array}$}} & \multirow{2}{*}{\multicolumn{2}{|c|}{$\begin{array}{l}\text { Negative } \\
\text { (6) Tobit }\end{array}$}} \\
\hline & \multicolumn{2}{|c|}{ (1) OLS } & \multicolumn{2}{|c|}{ (2) OLS } & \multicolumn{2}{|c|}{ (3) OLS } & \multicolumn{2}{|c|}{ (4) OLS } & & & & \\
\hline & 0.426 & $* * *$ & 0.991 & $* * *$ & 0.993 & $* * *$ & 1.618 & $* * *$ & 1.905 & $* * *$ & -0.33 & \\
\hline$L I S T \_C A R(-7,-1)$ & -1.604 & $* * *$ & -1.644 & $* * *$ & -1.863 & $* * *$ & -1.515 & $* * *$ & -1.345 & $* * *$ & -1.248 & $* *$ \\
\hline LIST_CAR $(0,0)$ & -3.006 & $* * *$ & -2.456 & $* * *$ & -2.445 & $* * *$ & -2.151 & $* * *$ & -2.076 & $* * *$ & -1.987 & $* * *$ \\
\hline$L I S T \_C A R(+1,+3)$ & 0.177 & & 0.284 & & 0.282 & & 0.278 & & 0.171 & & -0.511 & \\
\hline SPAN & & & -0.002 & $* * *$ & -0.002 & $* * *$ & -0.002 & $* * *$ & -0.002 & $* * *$ & -0.001 & \\
\hline LIST_RATING & & & -0.03 & $* *$ & -0.031 & $* *$ & -0.035 & $*$ & -0.048 & $* *$ & -0.032 & \\
\hline NEAR_JUNK & & & 0.253 & $* *$ & 0.294 & $* *$ & 0.31 & $* *$ & & & 0.383 & $* * *$ \\
\hline NEAR_INVESTMENT & & & -1.806 & $* * *$ & -1.837 & $* * *$ & -1.848 & $* * *$ & -2.944 & $* * *$ & & \\
\hline $\begin{array}{c}\text { LIST_CAR }(-7,-1)^{*} \\
\quad \text { NEAR_JUNK }\end{array}$ & & & & & 1.66 & $*$ & 2.066 & $* *$ & & & 1.271 & \\
\hline $\begin{array}{c}\text { LIST_CAR }(-7,-1)^{*} \\
\text { NEAR_INVESTMENT }\end{array}$ & & & & & -3.033 & & -2.827 & & -1.746 & & & \\
\hline LN(ASSETS) & & & & & & & -0.013 & & -0.009 & & -0.002 & \\
\hline ROA & & & & & & & -0.305 & & -0.312 & & -0.025 & \\
\hline DEBT_RATIO & & & & & & & -0.103 & & -0.245 & & -0.044 & \\
\hline CASH_RATIO & & & & & & & 0.276 & & -0.08 & & 0.051 & \\
\hline Year Dummy & No & & No & & No & & Yes & & Yes & & Yes & \\
\hline R-Square & 0.087 & & 0.194 & & 0.209 & & 0.217 & & 0.47 & & 0.340 & \\
\hline F-Value & 19.93 & $* * *$ & 21.58 & $* * *$ & 17.24 & $* * *$ & 11.1 & $* * *$ & & & & \\
\hline $\mathrm{N}$ & 598 & & 598 & & 598 & & 583 & & 583 & & 583 & \\
\hline $\begin{array}{l}\text { Equality of Coefficients } \\
\text { (F-Test) }\end{array}$ & Diffe & & Differ & nce & Differ & ence & Differ & ence & Diffe & & Differ & \\
\hline $\begin{array}{c}\mathrm{H}_{0}: \text { LIST_CAR }(-7,-1)= \\
\text { LIST_CAR }(0,0)\end{array}$ & 1.402 & $* * *$ & 0.812 & & 0.582 & & 0.636 & & 0.731 & & 0.739 & \\
\hline
\end{tabular}

This table presents results of regressing rating changes at delisting on the CAR surrounding the listing date and other control variables. The dependent variable in all models is the numerical change in rating that occurs upon delisting from CreditWatch. An upgrade (downgrade) is reflected by a negative (positive) number. LIST_CAR $(\mathrm{T} 1, \mathrm{~T} 2)$ is the CAR computed using the market model from days T1 to T2 relative to the day listed on CreditWatch. SPAN is the number of days between listing and delisting. LIST_RATING is the numerical rating at the time of listing. NEAR_JUNK is a dummy variable equal to one for negatively listed firms with an initial rating of $\mathrm{BBB}+$, BBB, or BBB-. NEAR_ INVESTMENT is a dummy variable equal to one for positively listed firms with an initial rating of $\mathrm{BB}+$, $\mathrm{BB}$, or $\mathrm{BB}-$. Financial variables are from the fiscal year ending prior to the listing date: LN (ASSETS) is the natural log of total assets, ROA is net income divided by total assets, DEBT_RATIO is total liabilities divided by total assets, CASH_RATIO is cash and equivalents divided by total assets. ***, **, * denotes statistical significance at the $1 \%, 5 \%$, and $10 \%$ levels, respectively.

To ascertain the economic significance of our results, consider the coefficient for LIST_CAR $(-7,-1)$ in Model 4 of -1.515 . A one percentage point decline in the pre-listing CAR is associated with a rating downgrade of about 0.015 notches. At first glance this may seem trivial, but the mean pre-listing CARs from Table 2 are substantially larger than $1 \%$. The fact that the pre-listing CARs are good predictors of rating changes upon delisting suggest that the CreditWatch is still not timely enough in reflecting the changes in firms' financial positions. ${ }^{9}$

Studies in the literature (e.g. Brister, Kennedy, and Liu, 1994; Jorion and Zhang, 2007) have shown that for the same magnitude of downgrade (e.g. downgrade by one notch), the impact on a low-grade bond (e.g. from B+

\footnotetext{
${ }_{9}^{9}$ As a robustness check, we perform ordered probit regressions using the same variable structures as Models 1,2 and 4 in Table 4 . The results confirm our previous findings.
} 
to B) tends to be greater than a high-grade bond (e.g. from A+ to A) because low-grade bonds are closer to bankruptcy and they are more scrutinized by investors and regulators. As a robustness check of our results, we examine whether the same principles holds true for the CAR surrounding the listing on CreditWatch. We choose the largest category with similar rating changes, the one notch downgrades, and construct three sub-categories based on the initial rating: high ratings $(\mathrm{A}+)$, medium ratings (BBB), and low ratings $(\mathrm{B}+)$.

The results of the analysis are presented in Table 5, and demonstrate that the initial level of the rating is an important determinant of the magnitude of the CAR surrounding the CreditWatch listing date. The magnitude of CARs during the pre-listing period increases monotonically as the credit level decreases. For instance, the CARs over the period $(-60,-1)$ are $-2.19 \%,-8.97 \%$, and $-19.52 \%$ respectively for high rated (from A+ to A), medium rated (from $\mathrm{BBB}$ to $\mathrm{BBB}-$ ), and low rated (from $\mathrm{B}+$ to $\mathrm{B}$ ) bonds. The pattern persists for the other pre-listing event windows as well, supporting the conclusions of prior research that for a given magnitude of rating change, the impact of rating changes is greater for lower rated bonds. The key difference, however, is that our results demonstrate equity markets are reasonably good at predicting the future rating change before the firm is placed on CreditWatch, especially for those firms listed with negative potential. The results once again suggest that CreditWatch does not reflect the change in the financial positions of listed firms' timely enough.

\section{Conclusions}

We examine whether rating agencies are sacrificing timeliness by pursuing rating stability by investigating the response of the equity market to the listing and delisting of firms on S\&P's CreditWatch, a service whose intended purpose is to improve the timeliness of information about changes in credit ratings. We find that while it made some improvement on the intended purpose, CreditWatch is still not completely effective at achieving this goal.

Table 5. Reaction to one-notch downgrade based on initial bond quality.

\begin{tabular}{|c|c|c|c|c|c|c|}
\hline \multirow{3}{*}{$\begin{array}{c}\text { AR } \\
\text { Day } \\
-7\end{array}$} & \multicolumn{6}{|c|}{ Downgrade-by-One-Notch } \\
\hline & \multicolumn{2}{|l|}{ Downgrade from $A+$ to $A$} & \multicolumn{2}{|l|}{ Downgrade from BBB to BBB- } & \multicolumn{2}{|l|}{ Downgrade from $B+$ to $B$} \\
\hline & $0.18 \%$ & & $-0.58 \%$ & $*$ & $-1.00 \%$ & \\
\hline-6 & $-0.89 \%$ & $* *$ & $-0.74 \%$ & & $-1.23 \%$ & \\
\hline-5 & $0.23 \%$ & & $-0.67 \%$ & & $-3.21 \%$ & $* *$ \\
\hline-4 & $-0.46 \%$ & & $-0.91 \%$ & $* *$ & $-1.84 \%$ & $* *$ \\
\hline-3 & $-0.68 \%$ & & $-0.64 \%$ & & $-1.38 \%$ & \\
\hline-2 & $0.00 \%$ & & $-0.28 \%$ & & $2.96 \%$ & $*$ \\
\hline-1 & $-0.99 \%$ & & $-1.92 \%$ & $* * *$ & $-2.30 \%$ & $* * *$ \\
\hline 0 & $-2.67 \%$ & $* * *$ & $-0.28 \%$ & & $-8.69 \%$ & $* * *$ \\
\hline 1 & $-0.35 \%$ & & $0.26 \%$ & & $-3.17 \%$ & $* * *$ \\
\hline 2 & $-0.38 \%$ & & $-0.81 \%$ & $* *$ & $2.54 \%$ & $* *$ \\
\hline 3 & $-0.85 \%$ & $*$ & $0.33 \%$ & & $4.54 \%$ & $* * *$ \\
\hline CAR & \multicolumn{6}{|c|}{ Downgrade-by-One-Notch } \\
\hline Day & Downgrade from $A+$ to $A$ & & Downgrade from BBB to BBB- & & Downgrade from $B+$ to $B$ & \\
\hline$(-60,-1)$ & $-2.19 \%$ & & $-8.97 \%$ & $* * *$ & $-19.52 \%$ & $* * *$ \\
\hline$(-30,-1)$ & $-3.73 \%$ & & $-7.91 \%$ & $* * *$ & $-13.37 \%$ & $* *$ \\
\hline$(-7,-1)$ & $-2.62 \%$ & * & $-5.74 \%$ & $* * *$ & $-8.00 \%$ & $* * *$ \\
\hline$(0,0)$ & $-2.67 \%$ & $* * *$ & $-0.28 \%$ & & $-8.69 \%$ & $* * *$ \\
\hline$(+1,+3)$ & $-1.57 \%$ & $* *$ & $-0.22 \%$ & & $3.91 \%$ & \\
\hline $\mathrm{N}$. & 10 & & 23 & & 12 & \\
\hline
\end{tabular}

This table examines the effect of bond quality on the magnitude of daily abnormal returns (AR) and cumulative abnormal returns (CAR) over various event windows surrounding the listing date. Abnormal returns are computed using the market model (MKT) as described in Section 1. Downgraded by one notch samples are decomposed into different subgroups according to their original listing position. Variables are defined same as before. *,**,*** denotes statistically different from zero based on a standard t-test at the $10 \%$, $5 \%$ and $1 \%$ levels, respectively. 
We report three empirical results that support our conclusion. First, we find that equity markets experience substantial positive (negative) abnormal returns for companies listed with positive (negative) potential on CreditWatch prior to the listing date. The pre-listing abnormal returns not only reflect the direction of potential rating changes, but also the magnitude of actual rating changes on the delisting date. These results suggest that rating agencies are still slow in conveying information to the market. Second, equity markets exhibit significant abnormal returns on the CreditWatch listing day, but little reaction to the delisting of a company from CreditWatch. The results suggest that the impact of rating agency's announcement has moved forward from rating change day to CreditWatch listings day. The results suggest that CreditWatch listing improved the timeliness of rating functions but has not completely resolved the issue of timeliness. Third, to further confirm the conclusion, we find that the pre-listing abnormal returns in equity markets are good predictors of both the direction and the magnitude of the eventual change in credit. This is especially true for those firms listed with negative potential, which is by far the most common listing type. Collectively, our findings suggest that rating agencies may sacrifice timeliness for the sake of stability and that even CreditWatch, which is designed to mitigate the disadvantage caused by rating stability, is not a completely effective instrument.

If an advance notice service such as CreditWatch is already substantially anticipated by the market and too slow in conveying information, credit rating agencies may need to reconsider whether a policy of issuing stable ratings is too costly. In order to repair the reputational damage suffered during the 2007-2008 financial crisis, credit rating agencies may have to develop more effective measures to convey changes in default probability to the market in a timely manner.

\section{Acknowledgements}

We are grateful for the helpful comments made by Kathy Fogel, Tomas Jandik, Wayne Lee, Alexey Malakhov, and Tim Yeager. The remaining errors, if any, are solely ours.

\section{References}

[1] Norden, L. and Weber, M. (2004) Informational Efficiency of Credit Default Swaps and Stock Markets: The Impact of Credit Rating Announcements. Journal of Banking and Finance, 28, 2565-2573. http://dx.doi.org/10.1016/j.jbankfin.2004.06.011

[2] Hull, J., Predescu, M. and White, A. (2004) The Relationship between Credit Default Swap Spreads, Bond Yields, and Credit Rating Announcements. Journal of Banking and Finance, 28, 2789-2811. http://dx.doi.org/10.1016/j.jbankfin.2004.06.010

[3] Reinhart, C.M. (2002) Credit Ratings, Default, and Financial Crises: Evidence from Emerging Markets. World Bank Economic Review, 16, 151-170. http://dx.doi.org/10.1093/wber/16.2.151

[4] Sy, A. (2004) Rating the Rating Agencies: Anticipating Currency Crises or Debt Crises? Journal of Banking and Finance, 28, 2845-2867. http://dx.doi.org/10.1016/j.jbankfin.2004.06.012

[5] Goldstein, M., Kaminsky, G. and Reinhart, C. (2000) Assessing Financial Vulnerability: An Early Warning System for Emerging Markets. Institute for International Economics.

[6] Cheng, M. and Neamtiu, M. (2009) An Empirical Analysis of Changes in Credit Rating Properties: Timeliness, Accuracy and Volatility. Journal of Accounting and Economics, 47, 108-130. http://dx.doi.org/10.1016/j.jacceco.2008.11.001

[7] Zweig, J. (2010) Melchior Palyi, the Man Who Called Financial Crisis—70 Years Earlier. The Intelligent Investor. Wall Street Journal. http://online.wsj.com/news/articles/SB10001424052748704405704575596382345085258

[8] Cantor, R. (2001) Moody’s Investors Service’s Response to the Consultative Paper Issued by the Basel Committee on Bank Supervision “A New Capital Adequacy Framework”. Journal of Banking and Finance, 25, 171-185. http://dx.doi.org/10.1016/S0378-4266(00)00121-7

[9] Cantor, R. and Mann, C. (2007) Analyzing the Tradeoff between Ratings Accuracy and Stability. Special Comment, Moody's Investor Services.

[10] Altman, E. and Rijken, H. (2004) How Rating Agencies Achieve Rating Stability. Journal of Banking and Finance, 28, 2679-2714. http://dx.doi.org/10.1016/j.jbankfin.2004.06.006

[11] Loffler, G. (2005) Avoiding the Rating Bounce: Why Rating Agencies Are Slow to React to New Information. Journal of Economic Behavior and Organization, 56, 365-381. http://dx.doi.org/10.1016/j.jebo.2003.09.015

[12] Cantor, R. and Mann, C. (2003) Are Corporate Bond Ratings Procyclical? Special Comment, Moody’s Investor Services. 
[13] Altman, E. and Rijken, H. (2006) The Added Value of Rating Outlooks and Rating Reviews to Corporate Bond Ratings. Working Paper, New York University Salomon Center.

[14] Dichev, D.I. and Piotroski, J.D. (2001) The Long-Run Stock Returns Following Bond Ratings Changes. Journal of Finance, 5, 173-203. http://dx.doi.org/10.1111/0022-1082.00322

[15] Hand, J.R.M., Holthausen, R. and Leftwich, R. (1992) The Effect of Bond Rating Agency Announcements on Bond and Stock Prices. Journal of Finance, 47, 733-752. http://dx.doi.org/10.1111/j.1540-6261.1992.tb04407.x

[16] Holthausen, R. and Leftwich, R. (1986) An Analysis of the Informational Value of Bond Rating Changes. Journal of Financial Economics, 17, 57-89. http://dx.doi.org/10.1016/0304-405X(86)90006-1

[17] Morgan, D.P. (2002) Rating Banks: Risk and Uncertainty in an Opaque Industry. American Economic Review, 92, 874-888. http://dx.doi.org/10.1257/00028280260344506

[18] Liu, P. and Thakor, A. (1984) Interest Yields, Credit Ratings, and Economic Characteristics of State Bonds: An Empirical Analysis. Journal of Money Credit and Banking, 16, 344-351. http://dx.doi.org/10.2307/1992222

[19] Brister, B., Kennedy, R. and Liu, P. (1994) The Regulation Effect of Credit Ratings on Bond Interest Yield: The Case of Junk Bonds. Journal of Business Finance and Accounting, 21, 511-531. http://dx.doi.org/10.1111/j.1468-5957.1994.tb00333.x

[20] Jorion, P. and Zhang, G. (2007) Information Effects of Bond Rating Changes: The Role of the Rating Prior to the Announcement. Journal of Fixed Income, 16, 45-59. http://dx.doi.org/10.3905/jfi.2007.683317 